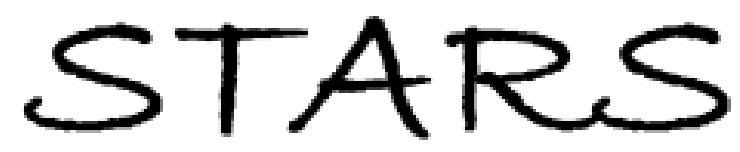

University of Central Florida

STARS

2013

\title{
The Effect Of Face Threat Mitigation On Instructor Credibility And Student Motivation In The Absence Of Instructor Nonverbal Immediacy
}

Laura Trad

University of Central Florida

Part of the Interpersonal and Small Group Communication Commons

Find similar works at: https://stars.library.ucf.edu/etd

University of Central Florida Libraries http://library.ucf.edu

This Masters Thesis (Open Access) is brought to you for free and open access by STARS. It has been accepted for inclusion in Electronic Theses and Dissertations, 2004-2019 by an authorized administrator of STARS. For more information, please contact STARS@ucf.edu.

\section{STARS Citation}

Trad, Laura, "The Effect Of Face Threat Mitigation On Instructor Credibility And Student Motivation In The Absence Of Instructor Nonverbal Immediacy" (2013). Electronic Theses and Dissertations, 2004-2019. 2700.

https://stars.library.ucf.edu/etd/2700

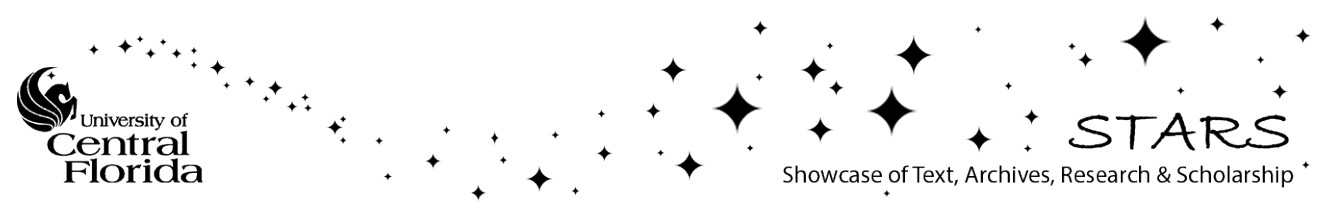


THE EFFECT OF FACE THREAT MITIGATION ON INSTRUCTOR CREDIBILITY AND STUDENT MOTIVATION IN THE ABSENCE OF INSTRUCTOR NONVERBAL IMMEDIACY

by

\author{
LAURA TRAD \\ B.S. University of Central Florida, 2010
}

A thesis submitted in partial fulfillment of the requirements for the degree of Master of Arts in Interpersonal Communication in the Nicholson School of Communication in the College of Sciences at the University of Central Florida Orlando, Florida

Summer Term

2013 
(C) 2013 Laura Trad 


\begin{abstract}
Many years of communication research have shown that an increase in immediacy has been a major factor that affects students' perceptions of instructor credibility which in turn affects, both students' cognitive and affective learning, student state motivation and a variety of other positive outcomes. However, in order for immediacy to be effective, instructor and student must be in the same location at the same time. With the recent push toward on-line classes, what can we find to act like immediacy in a text based format? This research suggests that face threat mitigation can be used in a text-based environment, to achieve the pro-social goals of instructor credibility and student state motivation to the same extent as it does when coupled with immediacy.
\end{abstract}

This study is a replication of a study done by Witt and Kerssen-Griep (2012). In the original study face threat mitigation (FTM) was coupled with instructor nonverbal immediacy (NVI) and they examined the impact these factors had on instructor credibility (i.e., competence, character, and caring) and student state motivation in a video simulated feedback situation. This study surveyed 218 undergraduate students in an introductory communication course. Students were randomly assigned to read hypothetical scenarios in which FTM was manipulated in a manner similar to Witt and Kerssen-Griep's study. They responded to three scales. The current study removed the instructor by using a simulated electronic feedback correspondence. Results of a MANCOVA and four separate ANOVAs were similar to those of the original findings. FTM was found to have a significant positive relationship with instructor credibility (i.e., competence, character, and caring) and student state motivation. 
This thesis is dedicated to my husband and family, who have lovingly sacrificed time and attention which enabled me to complete this degree. Without the support of my tireless husband none of this would be possible. 


\section{ACKNOWLEDGMENTS}

I would like to acknowledge and thank the members of my committee, without each of their unique talents and abilities this would not have been possible. My chair, Dr. James Katt has been invaluable in providing mentorship and direction for me. He has believed in my vision and my ability even when I didn't. Dr. Ann Miller, presented me with a challenge early in my academic career and has been there to support me in challenging myself through this whole process. Dr. Rita Graham is a never ending source of encouragement and has given me a greater understanding of what it means to be an educator, both academically and personally. It is through all of their special qualities that I have been able to learn and accomplish so much.

I would also like to extend a special thanks to my colleagues and friends; it is through the support of these amazing women that I was able to survive the past three years. We have all taken turns, wiping tears, holding hands and sharing joys. 


\section{TABLE OF CONTENTS}

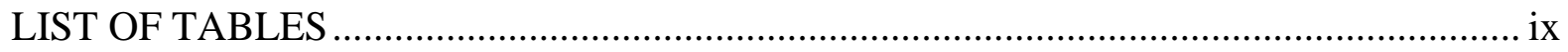

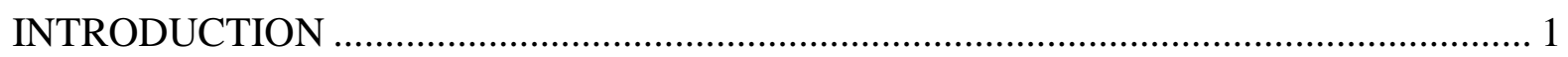

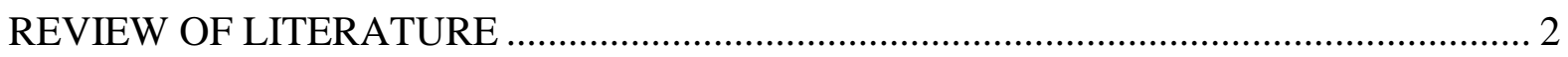

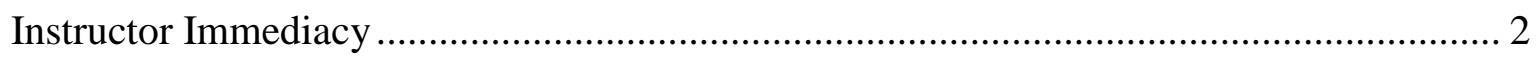

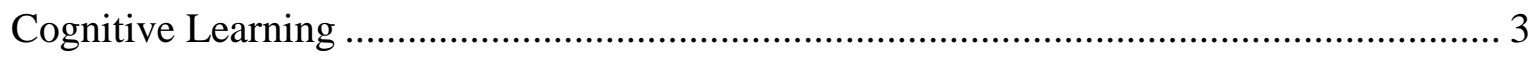

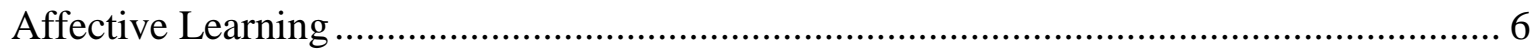

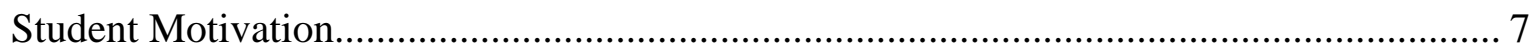

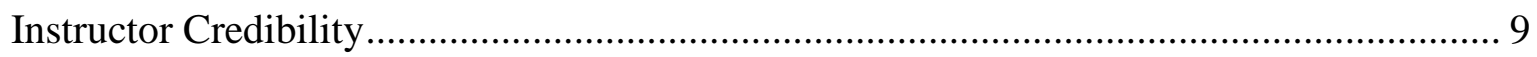

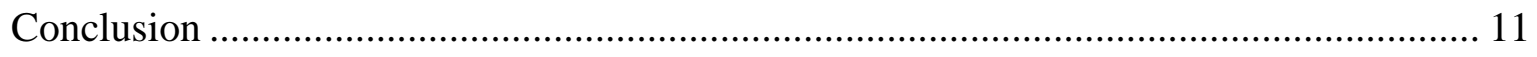

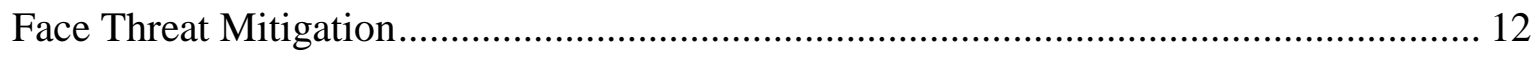

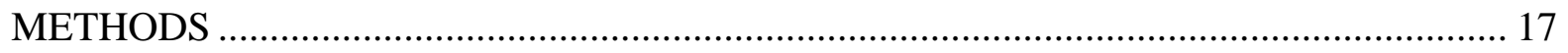

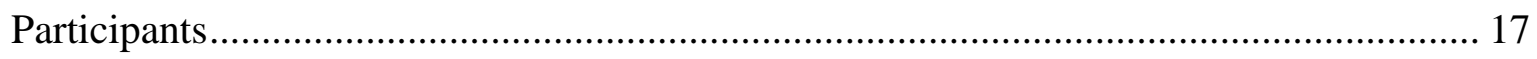

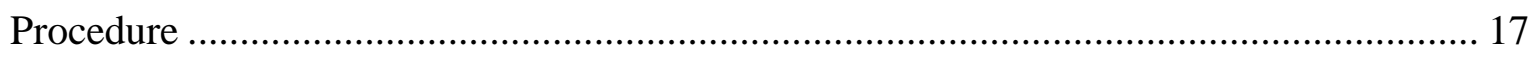

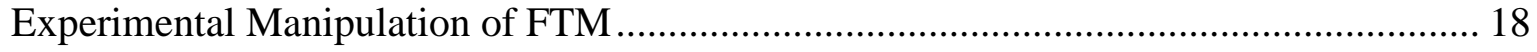

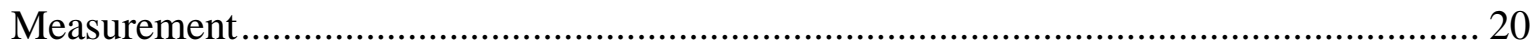

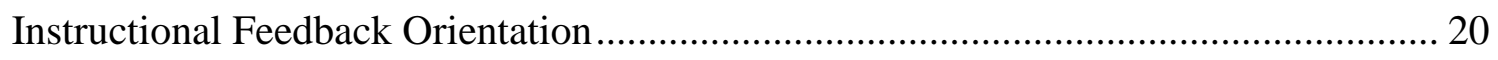

Student Perceptions of Teacher Credibility ……………......................................... 20

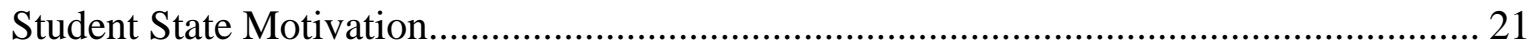




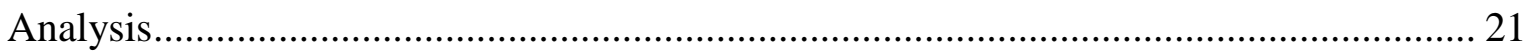

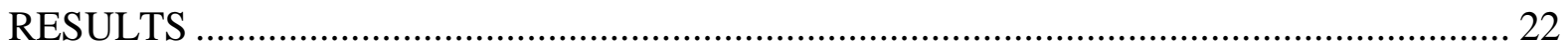

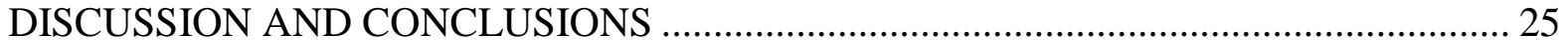

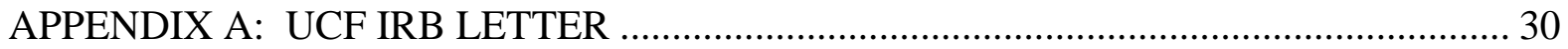

APPENDIX B: MOCK COMMUNICATIONS …....................................................... 32

APPENDIX C: INSTRUCTOR FEEDBACK ORIENTATION SCALE ........................... 35

APPENDIX D: STUDENT STATE MOTIVATION SCALE ........................................ 38

APPENDIX E: INSTRUCTOR CREDIBILITY SCALE .............................................. 40

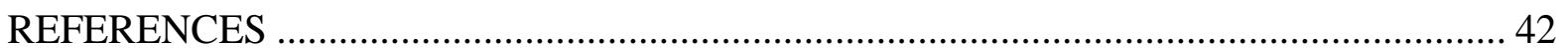




\section{LIST OF TABLES}

Table 1: Descriptive Statistics, Alphas, Pearson correlations Coefficients for all Variables . 22 


\section{INTRODUCTION}

Many years of communication research have shown that an increase in immediacy has been a major factor that affects students' perceptions of instructor credibility (Teven \& Hanson, 2004) which in turn affects, both cognitive and affective student learning (Chesebro, 2003; Witt \& Wheeless, 2001), student motivation (Chesebro \& McCroskey, 2001), and a variety of other positive student outcomes. However, in order for immediacy to be effective, instructor and student must be in the same location at the same time. With the recent push toward on-line classes, what can we find to act like immediacy in a text based format? In the first section in this chapter the construct of immediacy will be explored and its impact on student outcome variables. I will then turn to face threat mitigation and how this may be the solution to achieving the same pro-social goals in a text-based environment. 


\section{Instructor Immediacy}

\section{REVIEW OF LITERATURE}

Over the past two decades, research into teacher immediacy and its effects on education have yielded fruitful results. Immediacy was first introduced as a construct by Mehrabian (1969) who explained "immediacy is defined in a somewhat general form as the extent to which communication behaviors enhance closeness to and nonverbal interaction with another" (p. 203). Mehrabian (1971) suggested that by the same mechanism as approach-avoidance theory people tend to be drawn to people they like. In the classic theory of approach-avoidance an organism's behavior is driven toward situations that are favorable and away from those that are unpleasant (Elliot, 1999). In the classroom this increased liking can have an impact on how students approach their instructors, and their classes with increased levels of commitment and interest toward learning (Pogue \& Ahyun, 2006; Schutt, Allen, \& Laumakis, 2009). Immediacy has been established through two types of behaviors, those that are displayed nonverbally and those that are presented verbally. The more studied, instructor nonverbal immediacy (NVI) behaviors, (e.g., forward body lean, direct body orientation, eye contact, smiling, and movement around the classroom) have been shown to have an effect on student learning, both cognitive and affective as well as motivation, on task behavior and compliance (Gorham, 1988). Although less frequently studied instructor verbal immediacy behaviors (e.g., adjective variation, verb tense, inclusivity, and implied volunteerism) produced less consistent yet similar results (Witt, Wheeless \& Allen, 2004).

Although NVI has been a well-established construct, verbal immediacy has proven to be more challenging. This construct when studied, has been in a face to face environment, necessitating that a communicator be present to deliver the verbal message. Even in the few 
studies that have used verbal immediacy in a distance learning situation (Guerrero \& Miller , 1998; Freitas, Myers \& Avtgis,1998; Hackman \& Walker,1990; Baker, 2004) the instructor has been videotaped. One of the reasons verbal immediacy has proven to be challenging is because it is difficult to extricate its results from instructors' nonverbal behaviors (Witt et. al., 2004). Another obstacle is the most frequently used scale (Gorham, 1988), which has been highly debated. The intention of this scale was not to be a standalone measure but one that defines "a specific set of low-inference verbal variables which, in combination with previously identified nonverbal variables, clarify a single process-product model for effective instructional interaction.'(Gorham, 1988, p.40) It has been estimated that as much as $60 \%$ of communication is nonverbal (Hall, 1966). Thus, when in a face to face situation it is impossible to "not" send a nonverbal message. When comparing instructors, various levels of immediacy have been used however, what message does a low immediacy condition communicate?

\section{Cognitive Learning}

There are a variety of ways that researchers have measured learning. Using Bloom's taxonomy, Kraiger, Ford, and Salas (1993) classified learning into three types: cognitive, affective, and skill based. The construct of cognitive learning as defined by Sitzmann, Ely, Brown and Bauer, (2010) "refers to the understanding of task-relevant verbal information and includes both factual and skill-based knowledge" (p. 171). It has been operationalized as standardized test scores, lower order recall, recognition of facts, the instructors rating of performance, and students' perception of learning (Rodriguez, Plax \& Kearney, 1996; Gorham 1988; Sitzmann, Ely, et al., 2010). One of the major draw backs of measuring cognitive learning is the number of confounding factors that make this construct difficult to measure and compare. 
"While standardized measures of cognitive learning within specific content areas have been developed, comparisons across content areas in disparate fields (such as art and chemistry), suffer from a lack of comparability of the cognitive learning measures" (Richmond, Gorham, \& McCroskey, 1987, p. 4). These factors can be, but are not limited to the instructors' bias or subjectivity, and students' prior knowledge of the subject. Gorham (1988) says "We have often heard comments from students such as 'I got a C but I learned a lot' or 'I didn't learn anything but got an A"' (p. 43). Comments like these made it necessary for other methods of evaluation to be utilized. After Richmond et al.'s (1987) seminal work, a number of studies have used perceptions of learning as a cognitive outcome (Baker, 2004; Butland \& Beebe, 1992; Chesebro \& McCroskey, 2001; Christensen \& Menzel, 1998; Christophel, 1990; Comadina, Hunt, \& Simond, 2007; Gorham, 1988; McCroskey et al., 1996a, 1996b; Menzel \& Carrell, 1999; Richmond, 1990). Although very closely related to affective learning (explained below) it has been shown to be a good indicator of the progress students have made, controlling for differences in discipline, instructor bias, and students' prior knowledge of the subject matter. For example, it would be difficult to compare the grades of a student in a 4000 level biology lab class with the grades of a student in a 1000 level philosophy lecture class and measure the students' cognitive gains in any meaningful way. However, by asking the students about their perception of the amount of learning that they feel has occurred, and the amount of learning that might occur given the ideal situation, the researcher can make a more meaningful comparison, even if it is only of the students' perceived gains in cognitive learning. Although this "learning loss score" is an indirect measure of cognitive learning it has become a widely accepted means of measurement. 
Some early studies identified a relationship between immediacy and cognitive learning (Witt, et al. 2004). Using the 34 item scale developed by Richmond, Gorham, and McCroskey in 1987, Gorham (1988) studied the connection between both verbal and nonverbal immediacy, and cognitive learning. The first 20 items indicating verbal immediacy were followed by 14 items indicating nonverbal immediacy. This scale asked students to rank these items from 0 (never) to 4 (very often). Gorham (1988) measured cognitive learning by asking students two questions "On a scale from 0-9 how much did you learn in the class" (p. 45) and "How much do you think you could have learned in the class if you had the ideal instructor?" (p. 45). These two questions established a "learning loss" score by subtracting the first from the second. This score allows us to compare very dissimilar classes in a homogenized way. This study showed a significant relationship between both verbal immediacy and cognitive learning measured by learning loss and nonverbal immediacy and cognitive learning also measured by learning loss.

When using the learning loss method and studying immediacy as a whole, verbal and nonverbal combined, some of the highest correlations were found. (Witt et. al., 2004) However, as mentioned previously, there is some discussion about the validity of measuring verbal immediacy independent of nonverbal immediacy. Even though a significant relationship has been found between verbal immediacy and learning some researchers have suggested that this relationship may be mitigated or superseded by the instructor's nonverbal interactions (Kearney, Plax, Smith, \& Sorenson, 1988; Witt, et al., 2004). A limited number of studies specifically focused on verbal immediacy and cognitive learning using direct, performance based means with poor results. (Jordan, 1989; Titsworth, 2001; Witt \& Wheeless, 2001). Witt and 
Wheeless (2001) looked at verbal immediacy in combination with both high and low nonverbal immediacy and found no significant change in cognitive learning.

\section{Affective Learning}

Although cognitive learning is the main goal of many college classes, it can be argued that students affect toward their instructor, course work and learning environment play a role in their motivation and thus increase on-task behaviors that lead to learning (Rodriguez et al., 1996). "Affective learning involves changes in feelings, attitudes, and values that shape thinking and behavior" (Neuman \& Friedman, 2010, p. 2). Using Bloom's taxonomy, Kraiger, Ford, and Salas (1993), classified learner motivation and self-efficacy as examples of affective learning outcomes. Student affect had influence on cognitive learning in a study by Rodriguez et al. (1996). Just like cognitive learning, affective learning has been operationalized in various ways, many of which are variations of Anderson's (1979) scale. Kearney (1994) developed a five question, seven-point semantic differential scale based on Anderson's (1979) work. Many researchers have used variations of these two scales to measure affective learning. Richmond (1990) measured affective learning using four, seven-step bipolar scales established in research done earlier for the same series (Richmond \& McCroskey, 1984; Comadena, Hunt, \& Simond, 2007) used Andersen's (1979) adaptation and extension of the Scott, and Wheeless' (1977) measure of affective learning. Christophel (1990), Christensen, and Menzel (1998) used three, seven-point, semantic differential scales to measure this construct.

Weather the 20 question scale or four question version was employed; affective learning seems to be consistently influenced by immediacy. Students affect, in turn, seems to have an impact on the amount of cognitive learning that occurs (Sitzmann, Ely, Brown, \& Bauer, 
2010).This is especially likely to be evident when cognitive learning is measured via selfassessment. "Because self-assessments are judgments that learners must render, theory suggests that these judgments are influenced by learners' affective and motivational states" (p. 171)

Using nine items of Anderson's 20 item seven point differential scale, Butland and Beebe (1992) found a significant correlation $(r=.45)$ between NVI and affective learning. This same study showed a correlation $(\mathrm{r}=.53)$ between verbal immediacy and cognitive learning. Witt, Wheeless, and Allen (2004), in a meta-analysis of 81 studies, showed a significant relationship between immediacy and affective learning. Their data represented $\mathrm{N}=17,328$ and a statistically significant correlation was found $(\mathrm{r}=.49)$, when comparing verbal, nonverbal, and combined immediacy, with the three types of learning. Nonverbal immediacy and perceived learning produced similar results to studies of verbal immediacy and perceived learning according to Witt, Wheeless, and Allen (2004). Consistently, research has shown a connection between teacher immediacy and learning, irrespective of how learning is defined or operationalized.

\section{Student Motivation}

Although a connection has been established between immediacy and learning, it has been argued that it may not be a direct connection but one that is mediated by motivation (Rodriguez et. al, 1996). Motivation is defined as "the process whereby goal-directed activity is instigated and sustained"' (Pintrich \& Schunk, 2002, p. 5). Although the effects of both positive motivation and a lack of motivation can clearly be observed, determining what causes motivation or the lack thereof is more difficult to parse. The question is not what motivates students but, as Katt and Condly (2009) point out “what prevents our students from being motivated?’(p.213). 
Motivation as a communicative process shows similarities to approach and avoidance motivation studied in psychology. Elliot (1999) explains that approach motivation behavior is "instigated" by favorable outcomes or possibilities at one end of the spectrum and avoidance motivation is encouraged by negative outcomes at the other. For educators this means giving students a reason to be motivated toward a subject by making that subject a positive desirable event.

Motivation is broken down into two categories; trait motivation, which describes a student's “'enduring disposition", (Brophy, 1987) and state motivation, a student's willingness to expend effort toward a particular goal (Katt \& Condly, 2009). Particularly interesting to the scholarship of instructional communication is state motivation. In this case, the student's state motivation can be influenced by the behaviors of the instructor. Studies by Christophel (1990) and Frymier (1994) find state motivation to be an important factor influencing both cognitive and affective learning. Motivation in the classroom also promotes feelings of affiliation and feelings of self-efficacy (Kerssen-Griep, Hess, \& Trees, 2003)

Christophel (1990) argues that instructor behavior has an influence on how attractive the subject is and can provide incentives for students to be motivated about learning a given topic. Liking the instructor and wanting to gain respect and approval of the instructor are great motivators. Using the verbal and nonverbal immediacy scales (Gorham, 1988; Richmond et. al., 1987) and a 12 question, 7 point differential scale which was an expansion of the 3 question scale used by Beatty, Forst, and Stewart (1996), Christophel compared students' perception of instructor immediacy with students' state motivation. Christophel (1990) found that "students who perceived their teachers to be more verbally and nonverbally immediate also reported 
greater levels of class motivation" (p. 331). Extending Christophel's (1990) and Richmond's (1990) work in this field, Frymier (1994) tested the two working models of the interaction between motivation, immediacy, and learning. The learning model states that learning is directly influenced by instructor immediacy. The motivation model which, simply put, states that motivation mediates the relationship between immediacy and learning. Using path analysis Frymier (1994) tests both models in an observational survey study and found that the motivation model proved to be a better fit than the learning model, indicating that state motivation mediated the relationship between verbal immediacy and affective learning. It was proposed that a curvilinear relationship may exist between immediacy and learning (Comstock, Rowell, \& Bowers, 1995). However, in a study conducted by Christensen \& Menzel (1998) the relationship between immediacy and learning in a classroom setting appears to be linear. Comadena, Hunt \& Simonds' (2007) found that instructor perceived caring as well as clarity also has an impact on both student motivation and affective learning.

\section{Instructor Credibility}

One pivotal aspects of the learning environment is the perception of the instructor's credibility. The Aristotelian concept of ethos, or credibility, consists of three dimensions: wisdom, virtue, and goodwill; in modern studies they are referred to as competence, character, and caring (McCroskey \& Young, 1981). Separately and together this multidimensional construct of speaker credibility holds that a credible speaker is a source of influence on the receiver, with students' perception of instructor caring appearing to have the greatest influence on student outcomes (McCroskey \& Teven, 1999). In an educational setting, the speaker is often the instructor and the receivers are the students. The instructor, if credible, then becomes a 
source of influence on student behavior (McCroskey \& Young, 1981). "Research generally has supported the proposition that source credibility is a very important element in the communication process, whether the goal of the communication effort be persuasion or the generation of understanding"' (McCroskey \& Young, 1981, p. 24). One of the primary goals of instruction is to further the student's understanding of the material presented by the instructor. Thus, by being a credible source, the instructor is better able to foster understanding of the subject matter and instill a sense of value for the subject in the student. In other words, create an environment for both cognitive and affective learning to occur.

Goodwill, or perceived caring (McCroskey, 1992; McCroskey \& Teven, 1999), has been shown to have a strong correlation with immediacy (Thweatt \& McCroskey, 1998; Teven, 2001; Teven \& Hanson, 2004; Teven \& Monte, 2008). In other words, teachers who are more immediate are also perceived to be more caring. Students perceive an instructor to be more caring when they think that the instructor has their best interest at heart. If the instructor can empathize with them and is good at determining when they are having a problem, that instructor is perceived by the students as more caring and thus is perceived as more credible (Teven \& McCroskey 1997). Caring teachers are also evaluated more positively by the students (Teven \& McCroskey 1997). The students' evaluation of the teacher has an impact on the students' perception of the course, the instruction, and the learning (Banfield, Richmond, \& McCroskey, 2006; Teven, 2007; Teven \& McCroskey, 1997). Teven and Hanson (2004) state that the four skills of a competent teacher are, they explain complex material well, have good classroom management skills, can effectively answer questions from students, and are good 
communicators. Wheeless (1975) found that the perceived competence of a source was also positively related to recall and cognitive learning.

\section{Conclusion}

Instructor immediacy also has been shown to have a positive effect on other factors related to learning such as willingness to comply with instructor requests (Burroughs, 2007), civil behavior in the classroom (Boice, 1996), information seeking strategies (Myers \& Knox, 2001), willingness to participate in class discussions (Menzel \& Carrell, 1999), and reduced anxiety (Chesebro \& McCroskey, 2001). These benefits of immediacy serve to foster a positive learning environment in face to face classrooms.

The literature on the benefits of teacher immediacy in the classroom is clear. Nonverbal immediacy has a strong influence on learning, motivation and credibility. With little effort and no apparent cost to the instructor or students this construct is an easy shift on the part of the instructor that can serve education well. However, it necessitates that both students and instructor be present in the same place at the same time. Rapidly, the face of education is changing. With the push by college administration, increasing budget concerns and advances in technology accessibility, many classes are being taught through computer mediated instruction. Although this option solves some problems, like those of budget, transportation, and space availability it causes others. The result is a gap between what has been proven to reduce the psychological distance between instructors and their students and the need to accommodate the use of digital education. Instructors now need to find other strategies for increasing students' perception of instructor affect, instructor credibility, as well as how to increase student motivation. Since many on-line classes are primarily, or even entirely text based, the traditional means of nonverbal 
immediacy to connect to students are not available. Thus instructors must find ways of establishing immediacy and credibility without relying on nonverbal cues.

\section{Face Threat Mitigation}

One possible alternative might lie in Face Threat Mitigation (FTM). Kerssen-Griep, Trees \& Hess (2008) argue that "competent instruction must include the ability to mitigate face threats and negotiate mutually acceptable identities during key instructional interaction” (p.314). Students' impression of the instructor, as we have discussed earlier in this paper, have a great impact of the affect the student holds for the instructor, class, and subject matter which in turn have an impact on learning. Those that communicate well can use verbal and linguistic strategies to mitigate threats to face when communicating messages that are potentially threatening (Kerssen-Griep et al., 2008). Goffman (1955) posited one of the first theories on face to face interaction. He proffered that in an interaction both communicants try to maintain each other's presented image. Since Goffman's (1955) seminal work many others have studied social interactions (Brown \& Levinson, 1987; Lim \& Bowers, 1991) and the presentation of what we have come to call face in the modern study of communication. "Face is an image of self, delineated in terms of approved social attributes." (Goffman, 1955, p. 213) Facework is thus the social dance we do between two communicants so that both interactants feel they have met their social obligations to one another to maintain their created identities. In an effort to maintain these images we are usually careful not to infringe on another's face needs. Face Threat Mitigation as described by Witt and Kersen-Griep (2011), consists of strategies used by the instructor, in feedback situations, to affect students' perceptions of their instructor. In some literature, when this relationship is positive between student and instructor, it is called mentoring. This 
instructional mentoring relationship has a positive impact on "Learners' engagement, attention, effort, achievement, and receptivity to criticism" (Kerssen-Griep, et al. 2008, p. 312). Mentoring is a relationship built between instructor and student where by the instructor as expert is "invested" in the students' personal and professional growth (Kerssen-Griep et al., 2008). This mentoring relationship necessitates that students be corrected by their instructor and that the student accepts the correction in the manner it was intended. This situation should be handled with care. Both the students and the educator have face needs that must be met by the interaction. Managing these interpersonal relationships to accomplish educational goals and maintain classroom control is crucial to effective teaching (Cazden, 1979). "Meeting relational goals matters because students' feelings about the people, topics, and contexts involved in their learning mediate how well they understand and process what they are presented" (Witt et al., 2011, p.80) Facework, when well negotiated, has been shown to have positive results in the classroom (Kerssen-Griep, 2001; Kerssen-Griep, et. al. 2003; Kerssen-Griep et al., 2008). Conversely, if instructors are unable to negotiate a positive face for themselves and their students, the students will feel less affect toward the instructor and be less likely to accomplish the intended learning outcome. (Kerssen-Griep et al., 2008).

Instructor feedback is a crucial part of the learning experience, and is a necessary part of a "mentoring" relationship. However, feedback has the potential danger of destroying the relationship between student and instructor. It is a commonly held belief, among instructors, that this is a compromise. In order to create a caring or immediate relationship with the students an instructor must compromise some relational goals for educational ones. Recent research has suggested that this is not the case (Witt \& Kerssen-Griep, 2011; Kerssen-Griep, Trees, \& Hess, 
2008; Trees, Kerssen-Griep, \& Hess, 2009). Feedback and instructor/student relationships need not be mutually exclusive. Done well, feedback can help students feel encouraged and motivated to rise to the occasion and reach their potential. Done poorly, however, students may become discouraged or, at its extreme, feel degraded and be more likely to drop out. Constructive instructor feedback should lend itself to fostering credibility for the instructor which in turn lends more weight to the feedback itself. Poor face relationships through feedback interactions threaten the instructor's perceived credibility.

When instructional strategies such as FTM and NVI are used in feedback interactions positive academic and relational outcomes can both be achieved (Kerssen-Griep, Hess, \& Trees, 2003; Kerssen-Griep et al., 2008; Trees et al., 2009; Witt \& Kerssen-Griep, 2011).Unlike immediacy which relies heavily on nonverbal communication, FMT is a verbal construct (Brown \& Levinson, 1987; Trees \& Manusov, 1998). If FTM can be effectively recreated in a virtual environment it may be the element that can be used to bridge the psychological gap between student and teacher and help to foster that mentoring relationship in the ever growing digital world.

In a two-part study, Witt and Kerssen-Griep (2011; Kerssen-Griep \& Witt, 2012) assigned students at random to one of four conditions, each a combination of high and low immediacy combined with high and low face threat mitigation. The set of data was than analyzed in two ways.

In the first study after a measure of students' trait orientation toward feedback was taken the students were shown one of four videos of the same instructor. The students were then asked 
to rate the instructor's credibility using the McCroskey and Teven's (1999) scale. Higher levels of FTM and higher levels of NVI led to the students' perception of instructor credibility the scenario went as follows:

The essential content of the feedback message was identical in the two scenarios, but in the higher FTM condition the instructor varied his communication strategies in an effort to protect the student's identity when confronted with potentially face threatening criticism. For example, the lower FTM comment "When you lost your place, you completely lost your composure"' was replaced in the higher FTM script with this self disclosive expression of solidarity: "When you lost your place, it threw you off for a while, but you managed that better than I did in my first college speech.'’ Potentially threatening directives in the lower FTM script such as "You have to practice giving the speech ...'” were replaced in the higher FTM script with the tactful and less directive suggestion that "You might also consider ...' and the informal question soliciting "What went well from your perspective?', Complete video scripts containing both FTM and instructor nonverbal immediacy cues are available from the first author. The experimental manipulations and preliminary explanation to set the context were designed to approximate a length that the authors judged within the norm of teacher-student feedback conversations in the classroom. The higher FTM condition lasted four minutes, and lower FTM lasted three minutes. Varying the levels of instructor nonverbal immediacy cues offered did not affect the scenarios' overall length. (Witt, \& Kerssen-Griep, 2011, p. 83) 
The second study in the series looked at the relationship between student and instructor and maintaining a productive rapport, while still providing the students with the necessary feedback to encourage their academic growth.

While not as widely researched as teacher immediacy, FTM has been shown to have a positive influence on affective learning, perceived instructor credibility (Trees et al., 2009; Witt et al., 2011; Kerssen-Griep et al., 2012; and Sabee \& Willson, 2005) and, because it is a linguistic/ word based variable, it could conceivably be used in a computer mediated contexts. However, because the nonverbal cues are missing it is not clear what influence this will have on instructor competency.

Based on Witt et al.'s (2011) findings, one can infer in a computer mediated or text based environment that FTM can change the way students perceive their instructors, although it remains to be seen how effective FTM would be in a context where there were no NVI cues whatsoever, such as in a computer mediated class. Thus, I pose the following research questions. RQ1 - Absent non-verbal immediacy cues, to what degree will levels of FTM influence students' perceptions of instructor credibility (i.e., competence, character, and caring) during instructional feedback?

RQ2 - Absent non-verbal immediacy cues, to what degree will levels of FTM influence students' reported state motivation during instructional feedback? 


\section{METHODS}

\section{Participants}

Participants included students enrolled in undergraduate a 1000 level introduction to communication course at a large Southeastern U.S. university. The sample consisted of 103 males $(47.2 \%), 114$ females $(52.3 \%)$, and one participant $(0.5 \%)$ who declined to indicate his or her sex. It included students with a variety of majors. Ages ranged from 18 to 31 years of age, with a mean age of 19.2 years. With regard to college rank, $105(48.2 \%)$ identified themselves as freshmen, $48(22.0 \%)$ sophomores, 31 (14.2\%) juniors, and $31(14.7 \%)$ seniors; 2 (0.9\%) did not indicate their class rank. Participants were assured anonymity. Extra credit was offered by instructor to students that participate as well as an alternate option for those that choose not to participate or who are disqualified from this research because of being under 18 years of age.

\section{Procedure}

Upon giving consent participants were randomly assigned to one of two conditions being provided with a paper survey booklet. They were asked to provide demographic information and complete an Instructional Feedback Orientation Scale (IFO) (King et al., 2009) to assess their trait responses to feedback interventions. The participants were given a set of instructions tailored for that interaction (see below). Each was asked to read a mock communication, containing a fictional feedback situation. The student was asked to imagine that the feedback is from a fictional instructor about a public speaking presentation they made. (Instructions to the students detailed below). The first condition contained low FTM feedback. The second contained the same feedback but with high FTM language. The participants were asked to imagine that they returned home from the presentation to find a letter in their course mail. Both conditions 
utilized the same scripts (with minimal modification) as Witt and Kerssen-Griep (2011) and Kerssen-Griep and Witt (2012) (see Appendix B). Once they read the mock communication the students completed a questionnaire assessing their perception of instructor credibility (McCroskey and Teven, 1999) as well as a measure of state motivation (Christophel, 1990).

\section{Experimental Manipulation of FTM}

This research manipulated a written communication similar to that which might be received by a student in his/her current public speaking class. Using the script, developed for the two part study by Witt and Kerssen- Griep (2011) and Kerssen-Griep and Witt (2012), a mock feedback communication was drafted. The content of each of the two the communications was the same, but the language used to convey the message represented either a low or high FTM conditions. A manipulation check was done by four graduate communication students who were provided with a FMT check list (Kerrsen-Griep, Hess \& Trees, 2003). The students were instructed to read the message as if it had been received following a speech they had given a class. Then they were asked to indicate on a scale of 1-7 if the message met the criteria listed below.

Manipulation check for FMT (Instructional face support during feedback): (Kerssen-Griep, Hess, \& Trees, 2003 p. 380)

To what degree does the instructor:

1. Work to avoid making students look bad

2. Leave the student free to choose how to respond 
3. Make sure the student is not cast in a negative light

4. Seem concerned about the students feelings

5. Let's the student know s/he thinks highly of them

6. Leave the student without a choice of how to respond to evaluation

7. Show understanding

8. $\quad$ Sound disapproving

9. Make the student feel pushed into agreeing with his/her suggestions

10. Show that $\mathrm{s} / \mathrm{he}$ cares about the student's learning experience

11. Express blunt criticism of the student's public speaking abilities

12. Make the student feel like s/he can choose how to respond to feedback

13. Make the student feel like an important member of the class

14. Make it hard for the student to propose their own ideas in light of his/her feedback

15. Seem attentive to the student as an individual

Note: Items 4, 6, 8,9,11 \&14 are reverse coded. Items measured perception of tact $(2,6,9,12$, 14), solidarity $(4,7,10,13,15)$, and approbation $(1,3,5,8,11)$ facework. 


\section{Measurement}

\section{Instructional Feedback Orientation}

Students' trait orientation to instructional feedback was measured using the Instructional Feedback Orientation Scale (King et al., 2009). The scale is a 33-item, 5-point likert-type assessment of the participants" "ordinary" response to instructional feedback. The scale ranges from 1 (strongly disagree) to 5 (strongly agree) in 4 categories of response to feedback. The categories break down as follows: ten items representing the dimension of utility, nine items for sensitivity, five items assessing confidentiality and three items on retention. (Appendix 1) Reliability scores for the IFO, were reported as .66 for utility, .85 for sensitivity, .85 for confidentiality, and .60 for retention (Witt \& Kerssen-Griep, 2011). A Cronbach's alpha reliability coefficient was calculated for the current study and reliability was .83 for utility, .87 for sensitivity, .83 for confidentiality, and .81 for retention.

\section{Student Perceptions of Teacher Credibility}

Participants' were administered the 18-item semantic differential scale assessing instructor credibility (McCroskey \& Teven, 1999). This scale measures the three dimensions of credibility with a 7-point bipolar pairing assessing competence, caring (goodwill) and character (trustworthiness), at 6 questions each.(Appendix 2) Previous reliability coefficients for the three subscales were reported as .83 for competence, .83 for character, and .77 for caring (Witt \& Kerssen-Griep, 2011). A Cronbach's alpha reliability coefficient was calculated for the current study and reliability for the three subscales are .90 for competence, .90 for character (trustworthiness), and .86 for caring 


\section{Student State Motivation}

Student's state motivation was measured using the Christophel's (1990) motivation scale. This 12-item semantic differential uses bipolar adjectives listed on a 7-point scale. The scale is used to measure how the student now feels about the hypothetical class. The previous reliability coefficient for the student motivation scale was .81 (Kerssen-Griep \& Witt, 2012). A Cronbach's alpha reliability coefficient was calculated for the current study and reliability for state motivation was 91 .

\section{Analysis}

In keeping with the replication the methods used by Witt and Kerssen-Griep (2011) and Kerssen-Griep and Witt (2012), a MANCOVA was conducted with the three dimensions of instructor credibility (competence, trustworthiness, and caring) and student motivation as dependent variables, FTM as the independent variable, and the instructional feedback orientation dimensions of retention and utility as covariates. The results are reported in Table 1. Individual ANOVAs were then obtained for the same reason and discussed in the next chapter. 


\section{RESULTS}

Descriptive statistics, including means Cronbach's alphas, and Pearson product-moment correlations for all variables included in the study, are reported in Table 1.

Table 1: Descriptive Statistics, Cronbach's alphas, Pearson Correlations Coefficients for all Variables

\begin{tabular}{|c|c|c|c|c|c|c|c|c|c|c|c|}
\hline Variables & Mean & S. D. & $\alpha$ & 1 & 2 & 3 & 4 & 5 & 6 & 7 & 8 \\
\hline 1-IFO-Utility & 39.33 & 4.33 & 0.83 & - & & & & & & & \\
\hline $\begin{array}{l}\text { 2-IFO-Sensitivity } \\
\text { 3-IFO- }\end{array}$ & 18.51 & 6.73 & 0.87 & -0.037 & - & & & & & & \\
\hline Confidentiality & 17.75 & 4.38 & 0.83 & 0.089 & $0.446 * *$ & - & & & & & \\
\hline 4-IFO-Retention & 6.23 & 2.60 & 0.81 & $-0.341 * *$ & $0.375^{* *}$ & 0.025 & - & & & & \\
\hline 5-Competence & 32.50 & 7.11 & 0.90 & $0.253 * *$ & $-0.154 *$ & -0.112 & $0.322 * *$ & - & & & \\
\hline 6-Trustworthiness & 33.62 & 6.25 & 0.90 & $0.302 * *$ & $-0.213 * *$ & -0.093 & $0.389 * *$ & $0.891 * *$ & - & & \\
\hline 7-Caring & 32.25 & 7.07 & 0.86 & $0.228 * *$ & $-0.179 *$ & -0.048 & $0.376^{* *}$ & $0.775^{* *}$ & $0.843 * *$ & - & \\
\hline 8-Motivation & 55.25 & 12.31 & 0.91 & $0.358 * *$ & $-0.164 *$ & -0.106 & $0.366^{* *}$ & $0.565^{* *}$ & $0.618 * *$ & $0.647 * *$ & 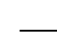 \\
\hline
\end{tabular}

*correlation is significant at the 0.05 level (2-tailed); ** correlation is significant at the 0.01 level (2-tailed)

The results of the factorial MANCOVA revealed significant multivariate main effects for FTM, Wilks' $\lambda=.764, \mathrm{~F}(4,195)=15.020, \eta^{2}=.236, p<.0001$. Following the methodology used by Witt and Kerssen-Griep (2011) and Kerssen-Griep and Witt (2012), covariance of two dimensions from the instructional feedback scale, retention and utility, were taken into account when obtaining these results. Four ANOVAs were conducted using FTM as the independent 
variable and each dimension of instructor credibility (competence, trustworthiness, and caring) and student motivation as dependent variables to further clarify the results.

The first research questions asked to what degree FTM influenced students' perceptions of instructor credibility (i.e., competence, character, and caring) during instructional feedback, absent non-verbal immediacy cues.

The first ANOVA revealed a significant main effect for FTM on instructor competence, $F(1$, $210)=5.616, \eta^{2}=.026, p=.019$.

The second ANOVA revealed a significant main effect for FTM on character, $F(1,214)=$ $13.103, \eta^{2}=.058, p<.0001$.

The third ANOVA revealed a significant main effect for FMT on caring, $F(1,213)=39.285$, $\eta^{2}=.156, p<.0001$.

Thus, supporting a positive relationship between FTM and instructor credibility (i.e., competence, character, and caring) during instructional feedback, absent non-verbal immediacy cues.

The second research question asked to what degree FMT influenced students' self-reported state motivation during instructional feedback absent non-verbal immediacy cues.

The fourth ANOVA revealed a significant main effect for FTM on student motivation, F (1, 208) $=26.187, \eta^{2}=.112, p<.0001$. 
Thus, a positive relationship between FTM and motivation, during instructional feedback, absent non-verbal immediacy cues was supported. 


\section{DISCUSSION AND CONCLUSIONS}

The present study was designed to evaluate the effects of FTM on instructor credibility (i.e., competence, character, and caring) and students' state motivation in a feedback situation without the influence of NVI cues. Extensive research has been done in the past on the effect immediacy has on the instructor-student relationship in the college classroom. We know the effects of positive immediacy are good for fostering a positive climate in building these relationships as well as fostering other educational outcomes. Positive NVI coupled with FTM has been shown to have a positive effect on all three dimensions of instructor credibility (Witt \& Kerssen-Greip, 2011) and motivation (Kerssen-Griep \& Witt, 2012). When FTM was coupled with low immediacy the effects were not statistically significant. (Witt \& Kerssen-Greip, 2011; KerssenGriep \& Witt, 2012). When either low FTM or low instructor NVI were coupled with a high level of the other, perceptions of instructor character suffered. Yet regardless of the level of instructor NVI, high FTM showed a positive influence on instructor caring (Witt \& KerssenGreip, 2011; Kerssen-Griep \& Witt, 2012).

This led to the first research question in the current study: absent nonverbal immediacy is FTM enough to influence student's perceptions of the instructor's credibility in all three dimensions? Analyses showed that FTM had the greatest influence on caring $\left(\eta^{2}=.156\right)$. Thus, face threat mitigation through tact, approbation, and solidarity tactics alone appear to produce similar results to the ones found in the prior study where FTM had a significant main effect on caring $\left(\eta^{2}=.16\right.$; Witt \& Kerssen-Greip, 2011). By Cohen's guidelines for social science research this is a moderate effect as opposed to the small effects usually obtained. When analyzed through an ANOVA, character was positively affected by FTM as well $\left(\eta^{2}=.058\right)$ 
again similar to the effects observed by Witt and Kerssen-Griep (2011), ( $\left.\eta^{2}=.07\right)$. Witt and Kerssen-Griep' results were only significant when FTM was coupled with the high immediacy condition. They recommended caution be used when interpreting results because of the interaction with NVI. However, the data in the current study may lead us to believe that FTM alone is sufficient to produce a positive effect on student perceptions of teacher credibility. Similar to the study by Witt and Kerssen-Griep (2011), competence was least affected by FTM. In the current study a small but statistically significant relationship $\left(\eta^{2}=.026\right)$ was found and in the Witt and Kerssen-Griep (2011) study $\left(\eta^{2}=.03\right)$. This is consistent with what one would expect of a students' perception of the competence of an instructor that that they know nothing about.

In the previous study by Kerssen-Griep and Witt (2012), motivation had a smaller effect size $\left(\eta^{2}=.05\right)$ than the current study where FTM produced an effect of $\left(\eta^{2}=.112\right)$ on motivation. Just as in the original study, utility of feedback was controlled for. This was done in an effort to standardize the responses of students who perceive feedback to varying degrees of usefulness. It is speculated that the difference in method might account for this difference in results. There is a possibility that the sample's young age and newness to college, may contribute to a higher state motivation. The current research is devoid of gender, unlike the video method used in the original study. It is unclear if gender has a connection to motivation, or if some other aspect of the videotaped instructor had a negative effect on motivation.

The differences in the two findings support Kerssen-Griep and Witt's supposition that instructor NVI (in this case, low NVI) may have a significant effect on students perception of the 
face supportive language instructors use. The results of this study further suggest that absence of NVI altogether is preferable to the presence of low NVI, and that low NVI is, in fact, negative NVI. By the way NVI has been operationalized in the past it would appears to be an increasing set of behaviors measured from low to high and that the low condition represented no immediacy. This research suggests that it may be time for reexamination of immediacy as a construct that is polarizing with no true neutral, where a lack of the immediacy behaviors may have a negative effect, as opposed to a neutral one.

\section{Limitations and Future Research}

Although the use of FTM (apart from NVI) showed positive results, this research should be viewed within the bounds of its limitations. The greatest limitation to this study is that a convenience sample was used. The treatment was randomly assigned so inferences can be made of this population, although they are not necessarily indicative of college students as a whole. For example, its demographics are not as diverse as they could be. Although the sex and of the sample 114 females $(52.3 \%)$ and males $(47.2 \%)$ is reflective of this college's population, the class standing (70.2\% freshmen and sophomores) and age (average age of 19.2 years) represented a younger and more inexperienced group than the college as a whole. Also, because only $16(7.3 \%)$ had previously taken a speech class, it is possible the participants lacked sufficient contextual experience to accurately imagine themselves in the scenarios. Future research should determine whether or not students with more public speaking experience would 
react differently from the students without public speaking experience in this study. If this study is replicated, a more diverse sample should be drawn.

This study utilized an experimental design which has limitations as well as inherent benefits. The experimental nature of this research allowed the researcher to manipulate the conditions of the feedback as well eliminates the possibility of any preconceived notions about the professor. Because the professor in the experiment was fictional and without description, there was no bias due to age, sex or race. These controls would not be possible in a real life scenario. However, experimental scenarios are dependent on the willingness and ability of the participants to imagine themselves in the treatment. Participants' lack of experience, lack of imagination, or lack of willingness to "play the game" may potentially limit the generalizability of the current study.

This research was also based on a single correspondence which may not have been salient for students with no frame of reference for either the professor or this type of public speaking class and thus may not produce results as valid multiple interactions with a real professor in a class with real consequences. Future research using natural settings and authentic situations should be undertaken for more ecological validity, before broad inferences are made. Future research should also be conducted in using FTM language in other aspects of electronic teaching to determine if it is only applicable to feedback messages or if these tactics can be applied to other types of educational messages an instructor uses on-line courses.

This research, although a small step, is one toward understanding what influences students in a text based environment such as we see with on-line classes. Previous research on FTM (Witt \& 
Kerssen-Greip, 2011; Kerssen-Griep \& Witt, 2012) has addressed the construct of FTM within the context of face-to-face interaction which by default must contain some level of immediacy. Although much is already known about factors related to instructor credibility, and the association of credibility with student motivation and learning, little information has been available about how these factors might operate in the virtual classroom. With the current trend toward on-line courses, it is crucial to explore if there are means that instructors can use to accomplish these same goals in a primarily text-based environment. The state of today's technology is such that posting videos in on-line courses is possible, yet is still a challenge for many instructors, and thus they choose not to do so. For these instructors as well as others this study provides good news, that it is possible that verbal feedback alone may have the power to impact student motivation as well as perceptions of instructor credibility. Given the many economic and logistic reasons, for higher education to move toward on-line courses and degrees, this study offers and important start to addressing some of those questions. 
APPENDIX A:

UCF IRB LETTER 
University of Central Florida Institutional Review Board

\section{Centiversity of Florida}

Office of Research \& Commercialization

12201 Research Parkway, Suite 501

Orlando, Florida 32826-3246

Telephone: $407-823-2901$ or 407-882-2276

www.research.ucf.edu/compliance/irb.html

\section{Approval of Exempt Human Research}

From: UCF Institutional Review Board \#1 FWA00000351, IRB00001138

To: $\quad$ Laura Trad and Co-PI: James A. Katt

Date: June 27, 2013

Dear Researcher:

On $06 / 27 / 2013$, the IRB approved the following activity as human participant research that is exempt from regulation:

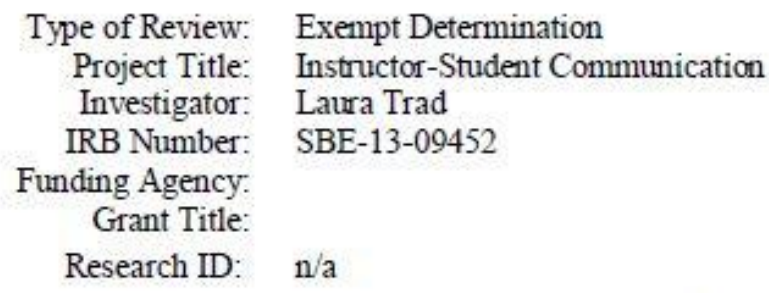

This determination applies only to the activities described in the IRB submission and does not apply should any changes be made. If changes are made and there are questions about whether these changes affect the exempt status of the human research, please contact the IRB. When you have completed your research. please submit a Study Closure request in iRIS so that IRB records will be accurate.

In the conduct of this research, you are responsible to follow the requirements of the Investigator Manual.

On behalf of Sophia Dziegielewski, Ph.D., L.C.S.W., UCF IRB Chair, this letter is signed by:

Signature applied by Patria Davis on 06/27/2013 10:53:45 AM EDT

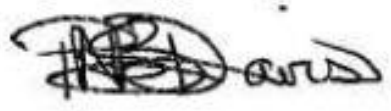

IRB Coordinator 
APPENDIX B:

MOCK COMMUNICATIONS 


\section{Instructions to the participant:}

Imagine the following scenario: You are taking a public speaking course and you have just given your first speech in class, the first graded event in the course. It had some rough spots, but you tried your best to give a strong speech. You didn't blow off the assignment and in fact took it seriously and invested yourself in the project. You return home and checked your course-mail. Your instructor has provided some written feedback about your speech, things to work on before your next one. Because it's early in the semester - the end of week two-you only have a general impression about your teacher. This is the first time you have received mail from your instructor directed to you, as an individual student.

The written evaluation your professor gives you is on the following page. Please read it carefully and respond to the survey questions that follow.

Mock communication Group A low FTM in class:

I don't think that speech you gave went very well. It looked to me like you lost your place, and when you did that you completely lost your composure. You're going to have to do better than that if you want to get a good grade in this course. Now here's what to do: Before you give your next speech, you have to practice giving the speech to at least one person. Also, I want you to write bullet points on your note card using different colors of ink, since that'll help. Once you have done these things, I want you to send me an e-mail message to set up a time for you to come to my office to discuss your preparation. These things should help. 
Mock communication Group B High FTM after class:

$\mathrm{Hi}$,

I would like to take a minute to provide you with some feedback on today's speech. First

speeches can be tough. You handled yours pretty well today, even when you lost your place -- it

looked like you couldn't come up with the example you'd intended to share, and that threw you off for a while. You managed it better than I did on my first speech in a college class. I remember almost blacking out when I lost *my* place. lol That's a fairly common experience, but it probably won't feel that intense again if you get lost next time- -it's just something that happens to all of us sometimes. One thing that can help ward off that feeling is to use a different color ink on your note card and write some bullet points about that example, just to refresh your memory as you go - the color can grab your eye and help settle your nerves with some certainty. You might also consider practicing giving your speech to at least one other person that helps you get over some of the initial nervousness that we all feel. Other things work as well - you'll certainly discover the things that work for you. It's important to me that you feel more confident and successful on your next one - how about emailing me to set up a time for you to come to my office and talk before your next speech? Now, what did you notice about your speech? What went well from your perspective? I'd like to hear how you feel?

Sincerely,

Professor Smith 
APPENDIX C:

INSTRUCTOR FEEDBACK ORIENTATION SCALE 
First we would like you to answer some questions about your attitudes about receiving feedback from your instructors. Please write a number next to each statement to indicate the extent to which you agree or disagree with that statement. Use the following scale:

5=agree strongly, 4=agree a little, 3=neither agree nor disagree, 2=disagree a little, $1=$ disagree strongly

1. I pay close attention to what teachers are saying when they provide feedback.

2. I think feedback from teachers is vitally important in improving my performance.

3. I will usually reflect on a teacher's feedback.

4. The possibility of receiving positive feedback is very encouraging.

5. I usually am able to improve my performance based on feedback.

6. I listen carefully when a teacher provides feedback.

7. I pay careful attention to instructional feedback.

8. I am extremely encouraged by positive feedback from teachers.

9. I think that feedback provides clear direction on how to improve my performance.

10. Feedback from my teachers can be a valuable form of praise.

11. Feedback from my teachers motivates me to improve my performance.

12. I view positive feedback from my teacher as a source of pride.

13. I pay close attention to what the teacher is saying.

14. I feel relieved when I receive positive feedback.

15. Corrective feedback from teachers means that they care about my performance.

16. Corrective feedback is most effective when it targets a specific example.

17. My feelings can be easily hurt by corrective feedback from a teacher.

18. I feel threatened by corrective feedback.

19. Corrective feedback hurts my feelings.

20. Corrective feedback is intimidating.

21. My feelings are not easily hurt by corrective feedback from a teacher.

22. It is difficult to "get over" corrective feedback.

23. Corrective feedback is embarrassing.

24. I tend to dwell on the negative feelings that result from corrective feedback.

25. Corrective feedback I receive from a teacher increases the stress I feel about future performances.

26. I do not like to receive corrective feedback in front of other people.

27. I do not like for others to hear what feedback I am receiving.

28. I like others to hear the feedback I am receiving from my teacher. 
29. I don't mind being singled out by feedback from a teacher.

30. I prefer to receive feedback from a teacher in private.

31. I can't remember what teachers want me to do when they provide feedback.

32. I tend to miss out on the details of what instructors want when they provide me with feedback.

33. I typically do not make note of the teacher's corrective comments. 
APPENDIX D:

STUDENT STATE MOTIVATION SCALE 
Now imagine that you are starting to work on the next assignment for the same class. For each line below, circle the number that most accurately reflects your feelings.

$\begin{array}{rrrrrrrrrl}\text { 1. } & \text { Motivated } & 1 & 2 & 3 & 4 & 5 & 6 & 7 & \text { Unmotivated } \\ \text { 2. } & \text { Interested } & 1 & 2 & 3 & 4 & 5 & 6 & 7 & \text { Uninterested } \\ \text { 3. } & \text { Involved } & 1 & 2 & 3 & 4 & 5 & 6 & 7 & \text { Uninvolved } \\ \text { 4. } & \text { Not Stimulated } & 1 & 2 & 3 & 4 & 5 & 6 & 7 & \text { Stimulated } \\ \text { 5. } & \text { Don't want to study } & 1 & 2 & 3 & 4 & 5 & 6 & 7 & \text { Want to study } \\ \text { 6. } & \text { Inspired } & 1 & 2 & 3 & 4 & 5 & 6 & 7 & \text { Uninspired } \\ \text { 7. } & \text { Unchallenged } & 1 & 2 & 3 & 4 & 5 & 6 & 7 & \text { Challenged } \\ \text { 8. } & \text { Un-invigorated } & 1 & 2 & 3 & 4 & 5 & 6 & 7 & \text { Invigorated } \\ \text { 9. } & \text { Unenthused } & 1 & 2 & 3 & 4 & 5 & 6 & 7 & \text { Enthused } \\ \text { 10. } & \text { Excited } & 1 & 2 & 3 & 4 & 5 & 6 & 7 & \text { Not excited } \\ \text { 11. } & \text { Aroused } & 1 & 2 & 3 & 4 & 5 & 6 & 7 & \text { Not aroused }\end{array}$


APPENDIX E:

INSTRUCTOR CREDIBILITY SCALE 
Now we'd like you to indicate, on the scales below, your feelings about the teacher who provided the feedback on the previous page. Numbers 1 and 7 indicate a very strong feeling. Numbers 2 and 6 indicate a strong feeling. Numbers 3 and 5 indicate a fairly weak feeling. Number 4 indicates you are undecided.

\begin{tabular}{|c|c|c|c|c|c|c|c|c|}
\hline 1. & Intelligent 1 & 2 & 3 & 4 & 5 & 6 & 7 & Unintelligent \\
\hline 2. & Untrained 1 & 12 & 3 & 4 & 5 & 6 & 7 & Trained \\
\hline 3. & Cares about me 1 & 2 & 3 & 4 & 5 & 6 & 7 & Doesn't care about me \\
\hline 4. & Honest 1 & 12 & 3 & 4 & 5 & 6 & 7 & Dishonest \\
\hline 5. & Has my interests at heart 1 & 12 & 3 & 4 & 5 & 6 & 7 & Doesn't have my interests at heart \\
\hline 6. & Untrustworthy 1 & 2 & 3 & 4 & 5 & 6 & 7 & Trustworthy \\
\hline 7. & Inexpert 1 & 12 & 3 & 4 & 5 & 6 & 7 & Expert \\
\hline 8. & Self-centered 1 & 2 & 3 & 4 & 5 & 6 & 7 & Not self-centered \\
\hline 9. & Concerned with me 1 & 2 & 3 & 4 & 5 & 6 & 7 & Not concerned with me \\
\hline 10. & Honorable 1 & 2 & 3 & 4 & 5 & 6 & 7 & Dishonorable \\
\hline 11. & Informed 1 & 2 & 3 & 4 & 5 & 6 & 7 & UnInformed \\
\hline 12. & Moral 1 & 2 & 3 & 4 & 5 & 6 & 7 & Immoral \\
\hline 13. & Incompetent 1 & 2 & 3 & 4 & 5 & 6 & 7 & Competent \\
\hline 14. & Unethical 1 & 2 & 3 & 4 & 5 & 6 & 7 & Ethical \\
\hline 15. & Insensitive 1 & 2 & 3 & 4 & 5 & 6 & 7 & Sensitive \\
\hline 16. & Bright 1 & 2 & 3 & 4 & 5 & 6 & 7 & Stupid \\
\hline 17. & Phony 1 & 2 & 3 & 4 & 5 & 6 & 7 & Genuine \\
\hline 18. & Not understanding 1 & 12 & 3 & 4 & 5 & 6 & 7 & Understanding \\
\hline
\end{tabular}




\section{REFERENCES}

Andersen, J. F. (1979). Teacher immediacy as a predictor of teaching effectiveness. In D. Nimmo (Ed.), Communication yearbook 3 (pp. 543-559). New Brunswick, NJ: Transaction Books.

Baker, J.D. (2004). An investigation of relationships among instructor immediacy and affective and cognitive learning in the online classroom. Internet and Higher Education, 71, 1 -13.

Banfield, S. R., Richmond, V. P., \& McCroskey, J. C. (2006). The effect of teacher misbehaviors on teacher credibility and affect for the teacher. Communication Education, 55, 63-72.

Beatty, M. J., Forst, E. C. Stewart, R. A. (1986). Communication apprehension and motivation as predictors of public speaking duration. Communication Education, 35, 143-146. doi: $10.1080 / 03634528609388332$

Boice, B. (1996). Classroom incivilities. Research In Higher Education, 37, 453.

Brophy, J. (1987). Synthesis of research on strategies for motivating students to learn. Educational Leadership, 45, 40-48.

Brown, P., \& Levinson, S.C. (1987). Politeness: Some universals in language use. Cambridge, England: Cambridge University Press.

Burroughs, N. F. (2007). A Reinvestigation of the Relationship of Teacher Nonverbal Immediacy and Student Compliance-Resistance with Learning. Communication Education, 56, 453-475.

Butland, M. J., \& Beebe, S. A. (1992). A study of the application of implicit communication theory to teacher immediacy and student learning. Paper presented at the annual meeting of the International Communication Association, Miami, FL. 
Cazden, C. (1979). Language in education: Variation in the teacher-talk register. In J. Alatis \& G.R. Tucker (Eds.), Georgetown university round table on languages and linguistics (pp. 144-162). Washington, DC: Georgetown University Press.

Chesebro, J. L. (2003). Effects of teacher clarity and nonverbal immediacy on student learning, receiver apprehension, and affect. Communication Education, 52, 135-147.

Chesebro, J. L., \& McCroskey, J. C. (2001). The relationship of teacher clarity and immediacy with student state receiver apprehension, affect, and cognitive learning. Communication Education , 50, 59-68.

Christensen, L. J. \& Menzel, K. E. (1998). The linear relationship between student reports of teacher immediacy behaviors and perceptions of state motivation, and of cognative, affective, and behavioral learning. Communication Education, 47, 82-90.

Christophel, D. M. (1990). The relationships among teacher immediacy behaviors, student motivation, and learning. Communication Education, 39, 323-340.

Comstock, J., Rowell, E., \& Bowers, J. (1995). Food for thought: Teacher nonverbal immediacy, student learning and curvilinearity. Communication Education, 44, 251-266. doi: 10.1080/03634529509379015

Comadena, M. E., Hunt, S. K., \& Simonds, C. J. (2007). The Effects of Teacher Clarity, Nonverbal Immediacy, and Caring on Student Motivation, Affective and Cognitive Learning. Communication Research Reports, 24, 241-248. doi:10.1080/08824090701446617 
Elliot, A.J. (1999). Approach and avoidance motivation and achievement goals. Educational Psychologist, 34, 169-189. doi: 10.1207/s15326985ep3403_3

Freitas, F. A., Myers, S. A., \& Avtgis, T. A. (1998). Student perceptions of instructor immediacy in conventional and distributed learning classrooms. Communication Education, 47, 366372.

Frymier, A. B. (1994). A model of immediacy in the classroom. Communication Quarterly, 42, $133-144$.

Frymier, A. B., \& Houser, M. (1998). Does making content relevant make a difference in learning? Communication Research Reports, 15, 121-129.

Frymier, A., \& Houser, M. L. (1999). The revised learning indicators scale. Communication Studies, 50, 1-12

Goffman, E. (1955) On face-work: An analysis of ritual elements in social interaction. Psychiatry: journal of interpersonal relations, 18, 213-231.

Gorham, J. (1988). The relationship between verbal teacher immediacy behaviors and student learning. Communication Education, 37, 40-53.

Guerrero, L. K., \& Miller, T. A. (1998). Associations between nonverbal behaviors and initial impressions of instructor competence and course content in videotaped distance education courses. Communication Education, 47, 30-42. 
Hackman, M. Z., \& Walker, K. B. (1990). Instructional communication in the televised classroom: The effects of system design and teacher immediacy on student learning and satisfaction. Communication Education, 39, 196-206.

Hall, E. T. (1966). The Hidden Dimension. Garden City, NY: Anchor Books.

Jaasma, M. A., \& Koper, R. J. (1999). The relationship of student-faculty out-of-class communication to instructor immediacy and trust and to student motivation. Communication Education, 48, 41-47.

Jordan, P. P. (1989). An examination of the relationship between perceived verbal and paralinguistic immediacy and accommodation to perceived cognitive learning. (Unpublished doctoral dissertation). West Virginia University, Morgantown, WV.

Kearney, P. (1994) Affective learning. In R. B. Rubin, P. Palmgreen, \& H. E. Sypher (Eds.), Communication research measures: A sourcebook (81-85). New York: Guilford Press.

Kearney, P., Plax, T. G., Smith, V. R., \& Sorenson, C. (1988). Effects of teacher immediacy and strategy type on college student resistance to on-task demands. Communication Education, 37, 54-67.

Kerssen-Griep, J. (2001). Teacher communication activities relevant to student motivation: Classroom facework and Instructional communication competence. Communication Education, 50, 256-273.

Kerssen-Griep, J., Hess, J. A., \& Trees, A. R. (2003). Sustaining the desire to learn: Dimensions of perceived instructional facework related to student involvement and motivation to learn. Western Journal of Communication, 67, 357-381. 
Kerssen-Griep, J., Trees, A. R., \& Hess, J. A. (2008). Attentive facework during instructional feedback: Key to perceiving mentorship and an optimal learning environment. Communication Education, 57, 312-332. doi:10.1080/03634520802027347

King, P. E., Schrodt, P., \&Weisel, J.J. (2009). The instructional feedback orientation scale: Conceptualizing and validating a new measure for assessing perceptions of instructional feedback. Communication Education, 58, 235-261.

Kraiger, K., Ford, J., \& Salas, E. (1993). Application of cognitive, skill-based, and affective theories of learning outcomes to new methods of training evaluation. Journal of Applied Psychology, 78, 311-328. doi:10.1037/0021-9010.78.2.311

Lim, T., \& Bowers, J. (1991). Facework: Solidarity, Approbation, and Tact. Human Communication Research, 17, 415-450.

McCroskey, J. C. (1992). An introduction to communication in the classroom. Edina, MN: Burgess International Group.

McCroskey, J. C, Payer, J. M., Richmond, V. P., Sallinen, A., \& Barraclough, R. A. (1996a). A multi-cultural examination of the relationship between nonverbal immediacy and affective learning. Communication Quarterly, 44, 297-307.

McCroskey, J. C, Sallinen, A., Payer, J. M., Richmond, V. P., \& Barraclough, R. A. (1996b). Nonverbal immediacy and cognitive learning: A cross-cultural investigation. Communication Education, 45, 200-211.

McCroskey, J. C, \& Teven, J. J. (1999). Goodwill: A reexamination of the construct and its measurement. Communication Monographs, 66, 90-103. 
McCroskey, J. C. \& Young, T. J. (1981). Ethos and credibility: The construct and its measurement after three decades. Central States Speech Journal, 32, 24-34.

Mehrabian, A. (1969). Some referents and measures of nonverbal behavior. Behavior Research Methods \& Instrumentation. 1, 203-207.

Mehrabian, A. (1971). Silent messages. Belmont, CA: Wadsworth.

Menzel, K. E., \& Carrell, L. J. (1999). The impact of gender and immediacy on willingness to talk and perceived learning. Communication Education, 48, 31-40.

Myers, S. A., \& Knox, R. L. (2001). The Relationship Between College Student InformationSeeking Behaviors and Perceived Instructor. Communication Education, 50, 343.

Neuman, K., \& Friedman, B. (2010). Affective learning: A Taxonomy for teaching social work values. Journal of Social Work Values and Ethics, 7, 1-12.

Plax, T. C., Kearney, P., McCroskey, J. C., \& Richmond, V. P. (1986). Power in the classroom VI: Verbal control strategies, nonverbal immediacy and affective learning. Communication Education, 35, 43-55.

Pogue, L. L., \& Ah Yun, K. (2006). The effect of teacher nonverbal immediacy and credibility on student motivation and affective learning. Communication Education, 55, 331-344.

Richmond, V. P., (1990). Communication in the classroom: Power and motivation. Communication Education, 39, 181-195.

Richmond, V. P., Gorham, J.S. \& McCroskey, J. C. (1987). The relationship between selected immediacy behaviors and cognitive learning. In M. L. McLaughlin (Ed.), Communication yearbook 10 (pp. 574-574). Newbury Park, CA: Sage. 
Richmond, V. P., \& McCroskey, J. C. (1984). Power in the classroom II: Power and learning. Communication Education, 33, 125-136.

Roach, K. D., \& Byrne, P. R. (2001). A cross-cultural comparison of instructor communication in American and German classrooms. Communication Education, 50, 1-14.

Rodriguez, J. I., Plax, T. G., \& Kearney, P. (1996). Clarifying the relationship between teacher nonverbal immediacy and student cognitive learning: Affective learning as the central causal mediator. Communication Education, 45, 293-305.

Pintrich, P. R., \& Schunk, D. H. (2002). Motivation in education: Theory, research and applications (2nd ed.). Upper Saddle River, NJ: Pearson

Schutt, M., B. Allen, \& M. Laumakis. (2009). The effects of instructor immediacy behaviours in online learning environments. Quarterly Review of Distance Education, 10, 135-48.

Scott, M. D., \& Wheeless, L. R. (1977). Communication Apprehension, Student Attitudes, and Levels of Satisfaction. Western Journal Of Speech Communication: WJSC, 41, 188-198.

Sitzmann, T., Ely, K., Brown, K. G., \& Bauer, K. N. (2010). Self-Assessment of Knowledge: A Cognitive Learning or Affective Measure? Academy Of Management Learning \& Education, 9, 169-191. doi:10.5465/AMLE.2010.51428542

Teven, J. J. (2001). The relationships among teacher characteristics and perceived caring. Communication Education, 50, 159-169.

Teven, J. J. (2007). Teacher caring and classroom behavior: Relationships with student affect and perceptions of teacher competence and trustworthiness. Communication Quarterly, 55, 433-450. 
Teven, J. J., \& Hanson, T. L. (2004). The impact of teacher immediacy and perceived caring on teacher competence and trustworthiness. Communication Quarterly, 52, 39-53.

Teven, J. J., \& McCroskey, J. C. (1997). The relationship of perceived teacher caring with student learning and teacher evaluation. Communication Education, 46, 1-9.

Teven, J., \& Monte, M. (2008). Teacher Caring in the College Classroom: A Review of the Construct and its Correlates. Paper presented at the annual meeting of the NCA 94th Annual Convention, TBA, San Diego, CA Online <PDF>. 2013-05-06 from http://citation.allacademic.com/meta/p257899_index.html

Thweatt, K. S., \& McCroskey, J. C. (1998). The impact of teacher immediacy and misbehaviors on teacher credibility. Communication Education, 47, 348-358.

Titsworth, B. (2001). The effects of teacher immediacy, use of organizational lecture cues, and students' notetaking on cognitive learning. Communication Education, 50, 283-297.

Trees, A. R., Kerssen-Griep, J., \& Hess, J. A. (2009). Earning influence by communicating respect: Facework’s contributions to effective instructional feedback. Communication Education, 58, 397-416.

Trees, A.R., \& Manusov, V. (1998). Managing face concerns in criticism: Integrating nonverbal behaviors as a dimension of politeness in female friendship dyads. Human Communication Research, 24, 564-583.

Velez, J. J., \& Cano, J. (2008). The Relationship between Teacher Immediacy and Student Motivation. Journal of Agricultural Education, 49, 76-86.

Wheeless, L. R. (1975). The relationship of four elements to immediate recall and studentinstructor interaction. Western Speech Communication 39, 131-140. 
Witt, P. L., \& Kerssen-Griep, J. (2011). Instructional Feedback I: The Interaction of Facework and Immediacy on Students' Perceptions of Instructor Credibility. Communication Education, 60, 75-94. doi:10.1080/03634523.2010.507820

Witt, P. L., \& Wheeless, L. R. (2001). An experimental study of teachers' verbal and nonverbal immediacy and students' affective and cognitive learning. Communication Education, 50, $327-342$.

Witt, P. L., Wheeless, L. R., \& Allen, M. (2004). A meta-analytical review of the relationship between teacher immediacy and student learning. Communication Monographs , 71, 184207. 